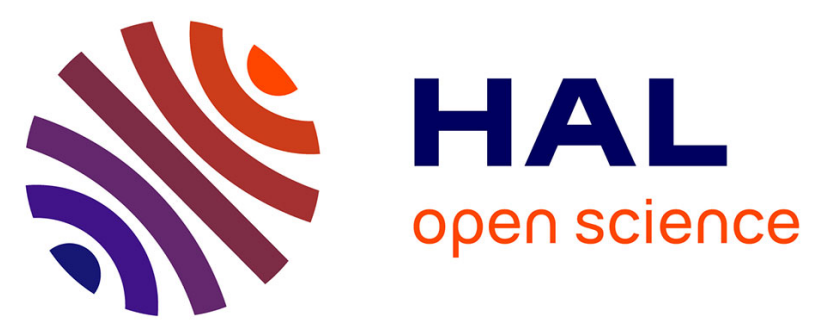

\title{
Functionalization of Bambusurils by a thiol-ene click reaction and a facile method for the preparation of anion-free Bambus[6]urils
}

Marie-Pierre Heck, Djamille Azazna, Marine Lafosse, Jialan Wang, Julie Rivollier, Imen Ben Cheikh, Michel Meyer, Pierre Thuéry, Jean-Pierre Dognon, Gaspard Huber

\section{To cite this version:}

Marie-Pierre Heck, Djamille Azazna, Marine Lafosse, Jialan Wang, Julie Rivollier, et al.. Functionalization of Bambusurils by a thiol-ene click reaction and a facile method for the preparation of anion-free Bambus[6]urils. Chemistry - A European Journal, 2018, 24, pp.10793 -10801. 10.1002/chem.201801468 . cea-01790936

\section{HAL Id: cea-01790936 https://hal-cea.archives-ouvertes.fr/cea-01790936}

Submitted on 11 Feb 2022

HAL is a multi-disciplinary open access archive for the deposit and dissemination of scientific research documents, whether they are published or not. The documents may come from teaching and research institutions in France or abroad, or from public or private research centers.
L'archive ouverte pluridisciplinaire HAL, est destinée au dépôt et à la diffusion de documents scientifiques de niveau recherche, publiés ou non, émanant des établissements d'enseignement et de recherche français ou étrangers, des laboratoires publics ou privés. 


\title{
Functionalization of Bambusurils by thiol-ene click reaction and new, facile method for the preparation of anion-free Bambus[6]urils
}

\author{
Djamille Azazna, ${ }^{[a, b]}$ Marine Lafosse, ${ }^{[a, b]}$ Julie Rivollier, ${ }^{[a]}$ Jialan Wang, ${ }^{[a]}$ Imen Ben Cheikh, ${ }^{[a]}$ Michel \\ Meyer, ${ }^{[c]}$ Pierre Thuéry, ${ }^{[d]}$ Jean-Pierre Dognon, ${ }^{[d]}$ Gaspard Huber ${ }^{[d]}$ and Marie-Pierre Heck *[a]
}

\begin{abstract}
New sulfide-functionalized bambus[4]urils ((RS) $\left.{ }_{8} \mathrm{BU}[4]\right)$ and bambus[6]urils ((RS) $\left.{ }_{12} \mathrm{BU}[6]\right)$ were synthesized through thiol-ene click coupling reactions (TEC) of allylbambus[n]urils. Thiosugars were grafted to $\mathrm{BU}[4]$ and $\mathrm{BU}[6]$. Synthesis of $\mathrm{BU}[6]$ derivatives always requires the use of a template anion (iodide, chloride or bromide) which is enclosed in the cavity of BU[6]. We show that this anion influences the reactivity of bambus[6]urils. An encapsulated iodide makes allyl functions of ally ${ }_{12} \mathrm{BU}[6]$ less reactive towards TEC and hydrogenation reactions in comparison to the corresponding chloride or bromide inclusion complexes. This is critical for the chemical reactivity of $\mathrm{BU}[6]$ and even more to determine their anion-binding properties. We report a new, facile and fast method using $\mathrm{AgSbF}_{6}$ to prepare anion-free BU[6]. NMR methods were used to estimate association constants of these new empty BU[6] with different anions. Quantum chemistry calculations were employed to rationalize the observed results. These new functionalized bambusuril scaffolds in alternate conformation could find applications as multivalent binders.
\end{abstract}

\section{Introduction}

Bambus[n]urils BU[4] and BU[6] constitute a family of neutral macrocycles formed by $n$ glycoluril units connected by $n$ methylene bridges $(n=4,6)$. BU[6] are able to bind anions within their cavity with a high affinity and selectivity, making them very attractive supramolecular receptors. ${ }^{[1]}$ Since the discovery of the first BU[6] by the group of Sindelar, ${ }^{[2]}$ the BUs family has expanded both in size and substitution. BU[4] and $\mathrm{BU}[6]$ can be substituted on the nitrogen atoms of their glycoluril unit by methyl, benzyl, propyl, or allyl groups and they are named $\mathrm{Me}_{12} \mathrm{BU}[6],{ }^{[2]} \mathrm{Bn}_{12} \mathrm{BU}[6]$, [3] $\mathrm{Bn}{ }_{8} \mathrm{BU}[4]$, ${ }^{[3]}$ $\mathrm{Pr}_{12} \mathrm{BU}[6],{ }^{[3]}$ ally| $\mathrm{l}_{8} \mathrm{BU}[4]$, and allyl ${ }_{12} \mathrm{BU}[6]$, respectively. ${ }^{[4]}$ They

[a] D. Azazna, M. Lafosse, Dr J. Rivollier, J. Wang, I. Ben Cheikh,

Dr. M.-P. Heck, SCBM, CEA, Université Paris-Saclay, , 91191 Gif-sur-Yvette, France. E-mail: Marie-Pierre.Heck@cea.fr

[b] D. A and M. L : equal contribution for this study

[c] Dr. M. Meyer, Institut de Chimie Moléculaire de l'Université de

Bourgogne, CNRS, Université de Bourgogne-Franche Comté, 9 avenue Alain Savary, BP 47870, 21078 Dijon cedex, France

[d] Dr. P. Thuéry, Dr J.-P. Dognon, Dr G. Huber, NIMBE, CEA, Université Paris-Saclay, 91191 Gif-sur-Yvette, France.

Supporting Information for this article is given via a link at the end of the document. are generally soluble in organic solvents. Bambus[6]urils bearing benzoate or carboxylate substituents on their portal are known to be water-soluble. ${ }^{[5,6]}$ Nitrobenzyl bambus[4]urils and bambus[6]urils were recently prepared in the group of Sindelar. ${ }^{[7]}$ Nitrobenzyl BU[4] derivatives have been successfully reduced into water soluble amino benzyl BU[4] that were further transformed into corresponding urea bambus[4]urils. ${ }^{[7]}$ Bambus[6]urils containing 12 (ethylene glycol) functions were recently reported to be as soluble in water as in nonpolar solvents. ${ }^{[8]}$ Although thiobambusurils are still unknown, some heterobambusurils called semithiobambus[4]urils and semithiobambus[6]urils have been prepared from semi-thioglycoluril derivatives, ${ }^{[9]}$ and used as precursors for semiaza-bambusurils bearing guanidines, which can act as anion channels. ${ }^{[10]}$ While bambus[6]urils strongly bind anions in their cavity, either in organic or aqueous media, ${ }^{[3,6,11]}$ the incorporation of sulfur atoms enables additional binding of metal ions at the portals. ${ }^{[12]}$

Bambusurils are usually prepared by an acid-catalyzed Mannich-type condensation of disubstituted glycoluril with paraformaldehyde in a solvent at reflux. We have previously improved this synthesis with the use of microwave irradiations that significantly shorten the reaction times and increase the yields of bambusurils. ${ }^{[4]}$ These microwave conditions have also been successfully used by the groups of Keinan and Sindelar ${ }^{[9,7]} A$ templating anion is always required either using reflux or microwaves, to promote the formation of the hexameric $\mathrm{BU}[6]$, in preference to the tetrameric $\mathrm{BU}$ [4]. Although this methodology has been well established, however BU[6] derivatives are generally isolated as having an anion present inside their cavity and time-consuming steps are necessary to obtain anion-free $\mathrm{BU}[6] .^{[3,8,13]}$

To our knowledge, only one monofunctionalization reaction on ally $_{8} \mathrm{BU}[4]$ by a cross metathesis reaction has been reported. ${ }^{[4]}$ The transformation of semithiobambusurils into semi(methyl)sulfoniumbambusuril and then to semiazabambusurils bearing guanidinium groups at their portal has been detailed by Keinan. ${ }^{[10]}$

Interestingly the first nonsymmetrical BU[4] was very recently prepared by Sindelar. ${ }^{[7]}$ Apart from these few examples, the functionalization and reactivity of BUs are still poorly developed. Therefore, we were interested in preparing new functionalized $\mathrm{BU}[4]$ and $\mathrm{BU}[6]$ and in studying the reactivity of $\mathrm{BU}[6]$ as a function of the enclosed anion.

To complete the family of allylbambus[n]urils starting from allyl $l_{8} B U[4] 1$ and I@allyl ${ }_{12} B U[6] . T B A ~ 2,{ }^{[4]}$ we herein report the synthesis of Cl@allyl ${ }_{12} \mathrm{BU}[6]$.TBA 3, and Br@ allyl ${ }_{12} \mathrm{BU}[6] . T B A$ 
4 and we show that the enclosed halide can alter the reactivity of ally| $\mathrm{l}_{12} \mathrm{BU}[6] 2-4$. (Figure 1). We synthesized new sulfidefunctionalized bambusurils 8-16 through a thiol-ene reaction of ally| $\mathrm{B}_{8} \mathrm{BU}[4] 1$ or halide@allyl ${ }_{12} \mathrm{BU}[6]$ 2-4. New $\mathrm{R}_{8} \mathrm{BU}$ [4] and $\mathrm{R}_{12} \mathrm{BU}[6]$ bearing respectively 8 or 12 thioether functions were obtained (Figure 1). We also report a new method using $\mathrm{AgSbF}_{6}$ to easily prepare anion-free $\mathrm{BU}[6]$ 17-21 (Figure 1). The binding properties of 17, 20 and 21 toward some halides were investigated by ${ }^{1} \mathrm{H}$ NMR spectroscopy. Quantum chemistry calculations were used to understand our results.

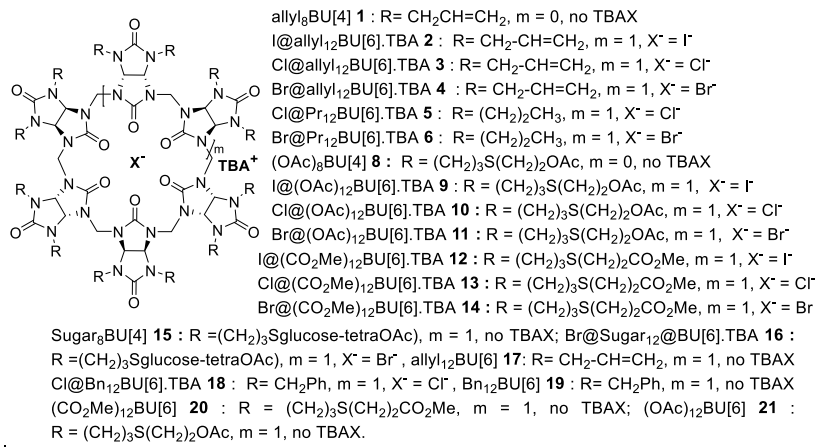

Figure 1: Structures of bambusurils $\mathrm{BU}[4]$ and $\mathrm{BU}[6]$ studied in this work.

\section{Results and Discussion}

We have previously reported the microwave-assisted synthesis of ally| $\left.\right|_{8} \mathrm{BU}[4] 1$ and $\mid @$ ally| ${ }_{12} \mathrm{BU}[6]$.TBA 2 starting from 2,4-diallylglycoluril and paraformaldehyde with $p$ toluenesulfonic acid. ${ }^{[4]}$ The 4-membered ally| ${ }_{8} B U[4] 1$ was prepared in chloroform ( $85 \%$ yield) in an experiment where no anion has been added, while 6-membered I@allyl ${ }_{12} \mathrm{BU}[6]$.TBA $2(60 \%$ yield) was obtained in toluene in the presence of tetrabutylammonium iodide (Scheme 1). ${ }^{[4]}$ Interested in studying whether the anion enclosed in the cavity of bambus[6]uril would modify its reactivity, we prepared

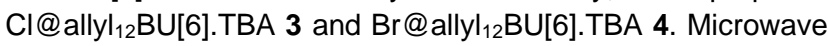
condensation of diallylglycoluril with paraformaldehyde in toluene in the presence of either tetrabutylammonium chloride or bromide provided $\mathrm{Cl}^{-} @ \mathrm{BU}[6] 3$ and $\mathrm{Br} @ \mathrm{BU}[6] 4$ in 63\% and $59 \%$ yield, respectively (Scheme 1).

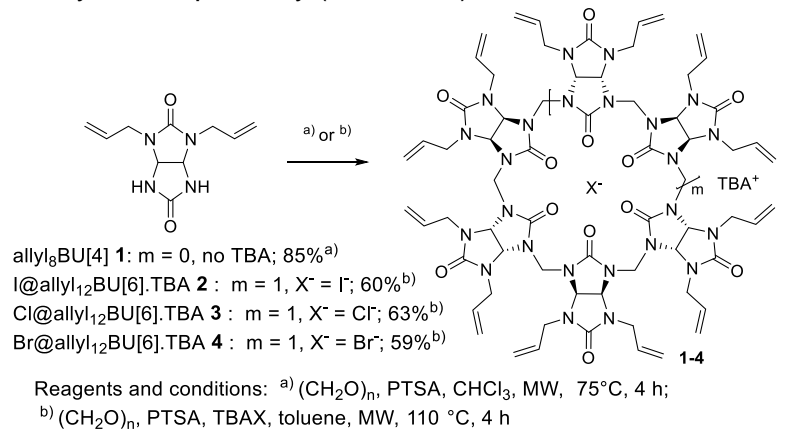

Scheme 1. Synthesis of allylıBU[4] 1 and X@ally| ${ }_{2} B U[6] . T B A ~ 2-4, X=I, C l$ or $\mathrm{Br}$.
Our results are coherent with Sindelar's work reporting that I@Bn ${ }_{12} \mathrm{BU}[6] . T B A$ and $\mathrm{Cl} @ \mathrm{Bn}_{12} \mathrm{BU}[6]$.TBA were isolated in comparable yields $\left(65 \%\right.$ and $53 \%$ respectively). ${ }^{[3]}$

Crystals of Cl@allyl ${ }_{12} \mathrm{BU}[6] . T B A 3$ were obtained by their slow evaporation in $\mathrm{CH}_{2} \mathrm{Cl}_{2} / \mathrm{MeOH} \quad(9 / 1 \mathrm{v} / \mathrm{v})$ and Br@allyl ${ }_{12} \mathrm{BU}[6]$.TBA 4 was recrystallized in $\mathrm{CH}_{2} \mathrm{Cl}_{2} / \mathrm{Et}_{2} \mathrm{O}(8 / 2$ $\mathrm{v} / \mathrm{v})$. The crystal structures of the isomorphous $\mathrm{BU}[6] \mathbf{3}$ and $\mathbf{4}$ were determined by single-crystal X-ray diffraction, and confirm that the macrocycles consist in six diallylglycoluril units in an alternate conformation, connected by one row of methylene bridges. As iodide in the isomorphous I@ally| ${ }_{12} \mathrm{BU}[6] . T B A ~ 2,{ }^{[4]}$ the chloride and bromide anions, which are located on an inversion center, are included in the cavity of the centrosymmetric macrocycles $\mathbf{3}$ and $\mathbf{4}$ (Figure 2).

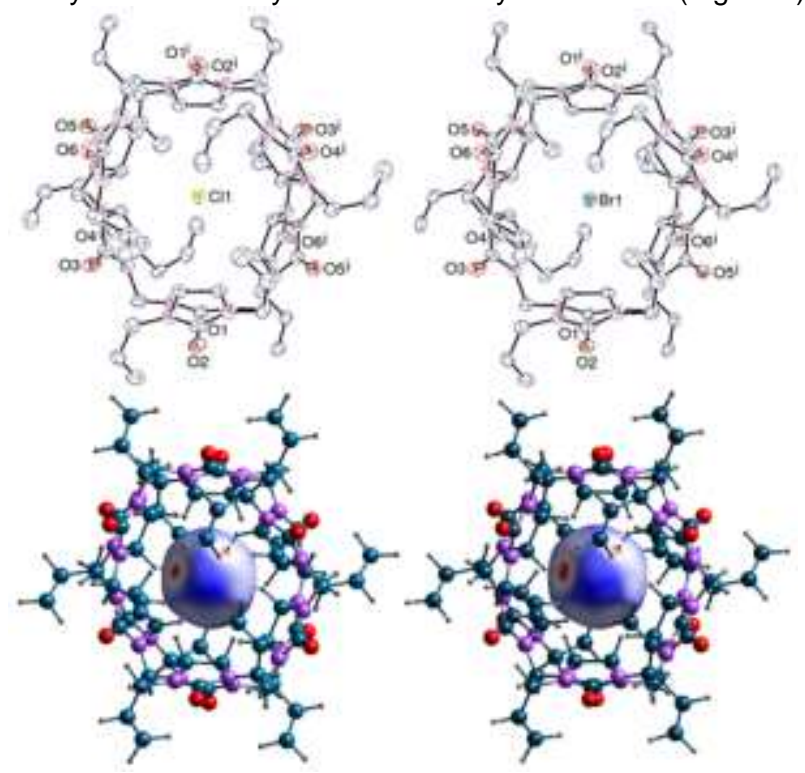

Figure 2. Top row: Crystal structures of Cl@allyl ${ }_{12} B U[6] 3$ (left) and Br@allyl ${ }_{12} B U[6] 4$ (right). Displacement ellipsoids are shown at the $30 \%$ probability level. Counterions and hydrogen atoms are omitted. Symmetry code: $\mathrm{i}=3 / 2-x, 1 / 2-y, 1-z$. Bottom row: Views of the Hirshfeld surface of the chlorine (left) and bromine (right) anions, showing the hydrogen bonding interactions with methine groups of $\mathrm{BU}[6]$ (dashed lines).

This arrangement is similar to that previously found in $\mathrm{Cl} @ \mathrm{Me}_{12} \mathrm{BU}[6],{ }^{[2]}$ and I@ $\operatorname{Pr}_{12} \mathrm{BU}[6]^{[3]}$ although complexation of two chloride anions, one at each portal, has been found for $\mathrm{Bn}_{12} \mathrm{BU}[6] .{ }^{[3]}$ The interactions between the included anion and the macrocycle can be analyzed through calculation of Hirshfeld surfaces (HSs) ${ }^{[14]}$ with CrystalExplorer. ${ }^{[15]}$ As shown in Figure 2, the HSs of the anions mapped with $d_{\text {norm }}$ show only four conspicuous red spots (only two of which are seen in the figure, the others being related to these by inversion) corresponding to contacts shorter than the van der Waals separation with four methine hydrogen atoms (the other methine hydrogen atoms are at distances larger than $3 \AA$ and are not involved in interactions stronger than dispersion). The geometry of these $\mathrm{CH}$...halide hydrogen bonds is similar to that in compound 2 , with distances varying with the halogen ionic radius, thus indicating that the macrocycle retains some

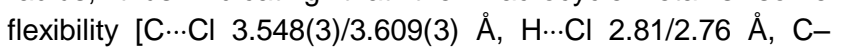
$\mathrm{H} \cdots \mathrm{Cl} 131 / 143^{\circ}$ in 3 ; $\mathrm{C} \cdots \mathrm{Br} 3.625(4) / 3.601(4) \AA$ 
2.87/2.76 $\AA, \quad \mathrm{C}-\mathrm{H} \cdots \mathrm{Br} \quad 133 / 141^{\circ}$ in $\mathbf{4}$, and $\mathrm{C} \cdots 1$

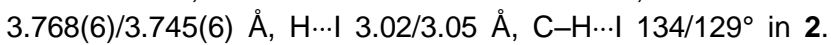
Although their existence has long been controversial, ${ }^{[16]}$ $\mathrm{CH}$...halogen hydrogen bonds are now considered significant, and it is notable that the distances found in the present cases are close to those usually reported. ${ }^{[17]}$ Although $\mathrm{CH}$...halide bonds are weak, the fact that the anion forms four such bonds in the present species favors their contribution to the stability of the complexes.

Owing to their rapid and efficient synthesis, ally ${ }_{8} \mathrm{BU}[4] 1$ and X@ally $\left.\right|_{12} \mathrm{BU}[6] . T B A$ 2-4 are valuable molecules for postfunctionalization.

First, we studied the reactivity of allylbambus[n]urils in hydrogenation conditions. We have previously shown that the reaction of allyl ${ }_{8} \mathrm{BU}[4] 1$ with $\mathrm{H}_{2}$ and $\mathrm{Pd} / \mathrm{C}$ (10 wt \% loading) in ethanol and as catalyst, afforded quantitatively $\operatorname{Pr}_{8} \mathrm{BU}[4]^{[4]}$ However, I@allyl ${ }_{12} \mathrm{BU}[6]$.TBA 2 remained unmodified when treated under these hydrogenation conditions, while the use of a larger amount of catalyst resulted in degradation of 2 . On the contrary, the hydrogenation of $\mathrm{Cl} @ a$ alyl $_{12} \mathrm{BU}[6]$.TBA 3 and Br@allyl ${ }_{12} B U[6] . T B A \quad 4$ afforded the expected Cl@Pr ${ }_{12} \mathrm{BU}[6] . T B A 5$ and $\mathrm{Br} @ \mathrm{Pr}_{12} \mathrm{BU}[6] . T B A$ 6, respectively, both in $90 \%$ yield (Scheme 2 ). We suspect that the iodide anion enclosed in the cavity of BU[6] 2 could have poisoned the catalyst, preventing the hydrogenation to proceed.

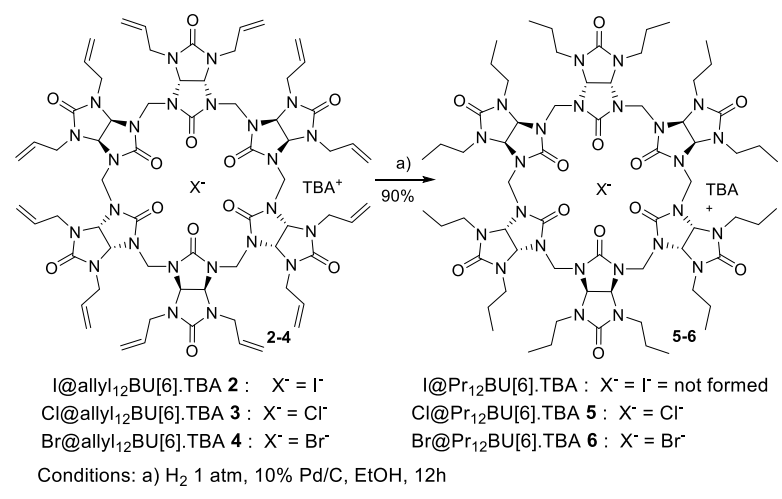

Scheme 2. Hydrogenation of halides@allyl ${ }_{12} \mathrm{BU}[6]$ 2-4.

Then we decided to transform the allyl arms of ally ${ }_{8} \mathrm{BU}[4]$ 1 and X@allyl ${ }_{12} \mathrm{BU}[6]$.TBA 2-4 with efficient methods able to create highly functionalized materials. Cross-metathesis reaction has already proven to be an effective tool to monofunctionalize ally ${ }_{8} \mathrm{BU}[4] \mathrm{1}^{[4]}$ We were interested in thiolene coupling reaction (TEC), an environmentally friendly click reaction that proceeds in mild conditions and which was successfully applied to the synthesis of bioconjugated polymers, star polymers, dendrimers, disaccharides and to the modification of surfaces. ${ }^{[18]}$ The AIBN-initiated TEC reaction of tetraallylglycoluril into thioethers was previously reported. ${ }^{[19]}$ The (allyloxy) ${ }_{12}$ Cucurbit[6]uril, a cavitand bearing twelve allyloxy groups at the equatorial positions, was transformed into Cucurbituril-based carbohydrate thanks to its TEC reaction with thioglycosides. ${ }^{[20]}$ To the best of our knowledge, apart from these two reports, the thiol-ene reaction has neither been tested on diallylglycoluril nor on bambusuril scaffolds. Therefore, we investigated TEC of diallylglycoluril as a simple model with a range of thiols using radical conditions initiated either by thermal or photochemical methods, with or without photoinitiator. ${ }^{[21]}$ As the reaction of diallylglycoluril with 2mercaptoethanol activated by AIBN in refluxing toluene or $\mathrm{CH}_{2} \mathrm{Cl}_{2}$ was unsuccessful, we examined UV initiations. The results are reported in Table 1 (method A). TEC reactions of diallylglycoluril under UV irradiation in $\mathrm{MeOH}$, using an excess of six equivalents of mercaptoethanol, methyl 3mercaptopropionate or NBoc-L-cysteine methyl ester efficiently afforded corresponding dithioether glycolurils 7a, 7e, and $7 f$ in $76 \%, 40 \%$ and $51 \%$ yield, respectively (Table 1 , entries 1, 5-6, method A). ${ }^{[22]}$

Table 1. TEC reactions of diallyglycoluril with UV activation (method $A$ ) or $\mathrm{TBC} / \mathrm{Et}_{3} \mathrm{~B}$ (method B).

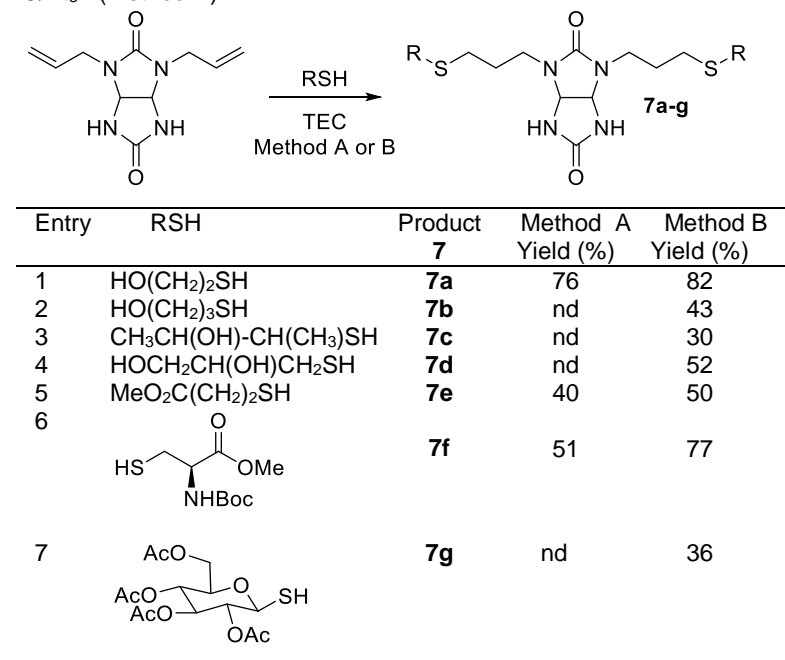

Reagents and conditions. Method A: Diallylglycoluril (1 equiv), $\mathrm{RSH}$ (6 equiv), MeOH, UV, 6 h. Method B: Diallylglycoluril (1 equiv), RSH (3 equiv), triethylborane (2.4 equiv), TBC (4-tert-butylcatechol, 2.4 equiv), $\mathrm{CH}_{2} \mathrm{Cl}_{2}, 12 \mathrm{~h}$ at RT. nd = not determined

Then, we tested the hydrothiolation method, reported by the group of Renaud, using triethylborane $\left(\mathrm{Et}_{3} \mathrm{~B}\right)$ as radical initiator and 4-tert-butylcatechol (TBC) as co-reagent. ${ }^{[23]}$ This method, which proceeds without heating or UV activation, was successfully used to link thiols on allyl glycosides as well as thiosugars to maleimide. ${ }^{[24]}$ Thus, thiol-ene reactions of diallylglycoluril were carried out with a variety of thiols using $\mathrm{Et}_{3} \mathrm{~B} / \mathrm{TBC}$ (Table 1, entries 1-8, method B). As indicated, all symmetric dithioether glycolurils $\mathbf{7 a - 7 g}$ were isolated in moderate to good yields (entries $1-7,30 \%-82 \%$ method $B$ ). Coupling of diallylglycoluril with 2-mercapto-3-butanol, a secondary thiol, afforded $7 \mathrm{c}$ in the lowest yield of $30 \%$ (entry 3 , method B). Thioglycerol and methyl 3-mercaptopropionate were successfully linked to diallylglycoluril to generate corresponding dithioether glycolurils 7 d-7e (52 and $50 \%$ yields, entries 4-5, method B). $N$-(tert-butoxycarbonyl)-L-cysteine methyl ester was grafted on $\mathbf{1}$ to give thioetherglycoluril $\mathbf{7 f}$ (entry $6,77 \%$ yield, method B). Treatment of diallylglycoluril with 1-thio- $\beta$-D-glucose tetraacetate afforded $7 g$ (entry $7,36 \%$ yield, method B). Renaud's conditions (method B) afforded 
TEC products in higher yields compared to the UV method (method $A)$, and more interestingly method $B$ required a weaker excess of thiol ( 1.5 vs 6 equivalents by alkene).

Moreover, a differently functionalized thioether glycoluril $\mathbf{7 h}$ was prepared via the one-pot TEC reaction of diallylglycoluril with sequential addition of 2-mercaptoethanol and methyl 3mercaptopropionate in $\mathrm{TBC} / \mathrm{Et}_{3} \mathrm{~B}$ conditions (Scheme 3, 7h : $42 \%$ yield). Symmetrical thioether glycolurils $7 \mathrm{a}$ and $7 \mathrm{e}$ were as well formed in 18 and $12 \%$ yields respectively.

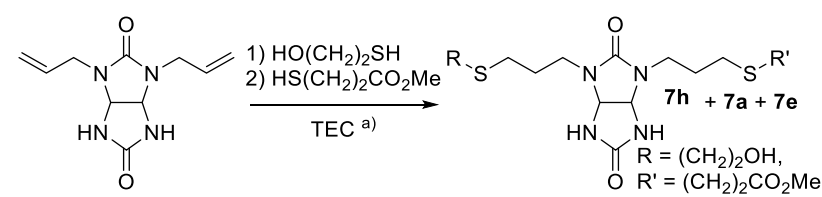

Scheme 3. Synthesis of glycoluril 7 h. TEC conditions ${ }^{\text {b) }}$ diallylglycoluril (1 equiv), $\mathrm{HO}\left(\mathrm{CH}_{2}\right)_{2} \mathrm{SH}$ (1 equiv), $\mathrm{HS}\left(\mathrm{CH}_{2}\right)_{2} \mathrm{CO}_{2} \mathrm{Me}$ (1 equiv), $\mathrm{Et}{ }_{3} \mathrm{~B}$ (2.4 equiv), TBC (2.4 equiv), $\mathrm{CH}_{2} \mathrm{Cl}_{2}, 12 \mathrm{~h}$, at RT.

Having thioether glycolurils $\mathbf{7}$ in hand, we then attempted to prepare the corresponding bambusuril. Thus glycolurils $7 a$ and $7 \mathrm{e}$ were reacted with paraformaldehyde and $p$ toluenesulfonic acid under MW irradiation, in $\mathrm{CHCl}_{3}$ or toluene, with or without TBAX (Scheme 4).

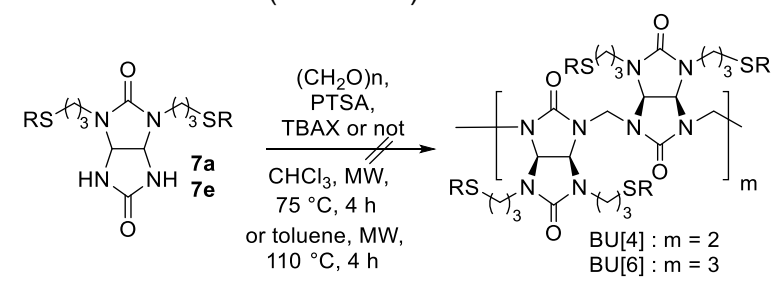

Scheme 4. Attempts to prepare bambusurils from dithioglycoluril 7a and 7e.

Unfortunately, the expected bambusurils were not obtained, but only a complex mixture of starting products and oligomers was formed. ${ }^{[25]}$ We supposed that the $\mathrm{N}$-substituted urea chains prevented the glycoluril units to closely interact with paraformaldehyde and hence the condensation reaction to proceed.

We then directly set up the hydrothiolation reaction of ally| ${ }_{8} B U[4] 1$ and $X @$ allyl $_{12} B U[6] . T B A ~ 2-4$ with various thiols so as to check the influence of the enclosed anion in $B U[6]$ (Scheme 5).

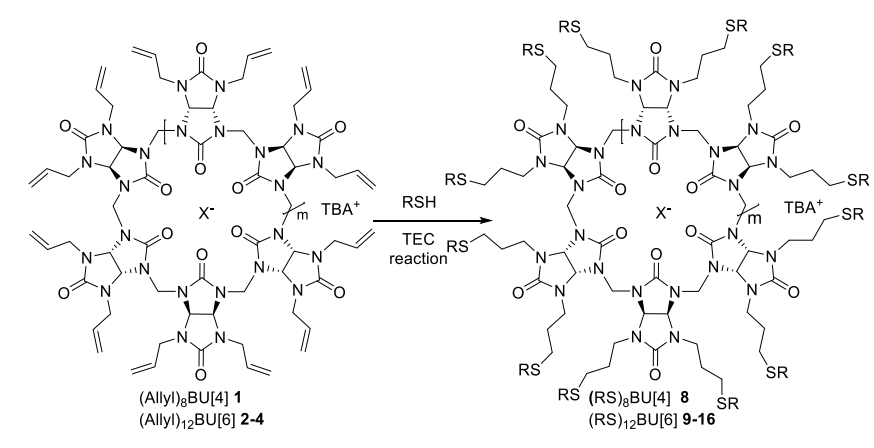

The most efficient TEC conditions using $\mathrm{Et}_{3} \mathrm{~B}$ and TBC (Method B, Table 1) were selected for the hydrothiolation of

\begin{tabular}{|c|c|c|c|c|}
\hline \multicolumn{2}{|c|}{ Entry (Allyl)BU } & \multirow{2}{*}{$\begin{array}{l}\mathrm{RS}= \\
\mathrm{S}\left(\mathrm{CH}_{2}\right)_{2} \mathrm{OAC}\end{array}$} & \multirow{2}{*}{$\begin{array}{c}\text { (RS)BU } \\
\mathbf{8}\end{array}$} & \multirow{2}{*}{$\begin{array}{c}\text { Yield (\%) } \\
89\end{array}$} \\
\hline$\overline{1^{[a]}}$ & Allyl ${ }_{8} \mathrm{BU}[4] 1$ & & & \\
\hline $2^{[a]}$ & I@allyl ${ }_{12} B U[6] 2$ & $\mathrm{~S}\left(\mathrm{CH}_{2}\right)_{2} \mathrm{OAC}$ & 9 & 20 \\
\hline $3^{[a]}$ & Cl@allyl ${ }_{12} \mathrm{BU}[6] 3$ & $\mathrm{~S}\left(\mathrm{CH}_{2}\right)_{2} \mathrm{OAC}$ & 10 & 57 \\
\hline $4^{[a]}$ & Br@allyl ${ }_{12} \mathrm{BU}[6] 4$ & $\mathrm{~S}\left(\mathrm{CH}_{2}\right)_{2} \mathrm{OAC}$ & 11 & 51 \\
\hline $5^{[\mathrm{b}]}$ & I@ allyl ${ }_{12} B U[6] 2$ & $\mathrm{~S}\left(\mathrm{CH}_{2}\right)_{2} \mathrm{CO}_{2} \mathrm{Me}$ & 12 & 49 \\
\hline $6^{[\mathrm{b}]}$ & Cl@ allyl ${ }_{12} \mathrm{BU}[6] 3$ & $\mathrm{~S}\left(\mathrm{CH}_{2}\right)_{2} \mathrm{CO}_{2} \mathrm{Me}$ & 13 & 55 \\
\hline $7^{[\mathrm{b}]}$ & Br@allyl ${ }_{12} \mathrm{BU}[6] 4$ & $\mathrm{~S}\left(\mathrm{CH}_{2}\right)_{2} \mathrm{CO}_{2} \mathrm{Me}$ & 14 & 52 \\
\hline $8^{[\mathrm{b}]}$ & Ally| ${ }_{8} B U[4] 1$ & $\mathrm{~S}\left(\mathrm{CH}_{2}\right)_{2} \mathrm{Sugar}(\mathrm{OAc})_{4}$ & 15 & 61 \\
\hline $9^{[b]}$ & $\mathrm{Br} @$ allyl $_{12} \mathrm{BU}[6] 4$ & $\mathrm{~S}\left(\mathrm{CH}_{2}\right)_{2} \mathrm{Sugar}(\mathrm{OAc})_{4}$ & 16 & 43 \\
\hline
\end{tabular}
allylbambusurils 1-4. The results are summarized in Table 2.

To our delight when ally| $\left.\right|_{8} \mathrm{BU}[4] \mathbf{1}$ was reacted with mercaptoethanol, followed by acetylation to facilitate the purification step, $\left.\left(\left(\mathrm{CH}_{2}\right)_{3} \mathrm{~S}\left(\mathrm{CH}_{2}\right)_{2} \mathrm{OAc}\right)\right)_{8} \mathrm{BU}[4] 8$ containing eight thioether moieties was isolated in good yield (entry 1,89\% yield both steps). TEC performed on I@allyl ${ }_{12} \mathrm{BU}[6] . T B A 2$ with mercaptoethanol afforded $\left.\left(\left(\mathrm{CH}_{2}\right)_{3} \mathrm{~S}\left(\mathrm{CH}_{2}\right)_{2} \mathrm{OAc}\right)\right)_{12} \mathrm{BU}$ [6].TBA 9 in a disappointing $20 \%$ yield (entry 2). Hydrothiolation of Cl@allyl ${ }_{12} \mathrm{BU}[6]$.TBA 3 or Br@allyl ${ }_{12} \mathrm{BU}[6] . T B A 4$ under the same conditions yielded functionalized $\mathrm{Cl} @$ (thioether) ${ }_{12} \mathrm{BU}[6] . T \mathrm{BA} 10$ and $\mathrm{Br} @$ (thioether) ${ }_{12} \mathrm{BU}[6] 11$ in 57 and $51 \%$ yield, respectively (entries 3,4 ). This result consolidate our hydrogenation study of halide@BU[6], and as above observed, TEC reaction is as well less efficient with I@BU[6].TBA 2, which encloses an iodide, than with $\mathrm{Cl}$ @BU[6].TBA 3 or Br@BU[6].TBA 4 containing a chloride or bromine anion respectively. TEC carried out with methyl 3mercaptopropionate and @ @allyl ${ }_{12} \mathrm{BU}[6] . T B A \quad 2$ or Cl@allyl ${ }_{12} \mathrm{BU}[6]$.TBA 3 or Br@allyl ${ }_{12} \mathrm{BU}[6] . T B A 4$ afforded corresponding BU[6] 12, 13 or 14, bearing 12 ester moities, in 49,55 and $52 \%$ yield respectively (entries $5-7$ ). Again, in that case, a lower yield was observed when iodide was enclosed in $\mathrm{BU}[6] 2$ and the reactivity was similar with chloride@BU[6].TBA 3 or bromine @ BU[6].TBA 4.

Finally, we succeeded in linking eight (1-thio- $\beta$-D-glucose tetraacetate) moities on ally ${ }_{8} \mathrm{BU}[4] 1$ to generate $(\mathrm{RS})_{8} \mathrm{BU}[4]$ 15 in $61 \%$ yield (entry 8 , Table 2). TEC reaction of Br@allyl ${ }_{12} \mathrm{BU}[6]$.TBA 4 with (1-thio- $\beta$-D-glucose tetraacetate) provide 12 sugars grafted (RS) ${ }_{12} \mathrm{BU}[6] 16$ (43\% yield, entry 9 , Table 2). The yield obtained for (RS) ${ }_{12} \mathrm{BU}[6] 16$ is slightly lower that for $(\mathrm{RS})_{8} \mathrm{BU}[4] 15$ (43\% versus $\left.61 \%\right)$ but it is still a good yield for a one step reaction adding 12 ligands on a skeleton. Indeed, it is the first time that sugars are linked to a bambusuril skeleton to generate an eight- or twelve- thiosugars bearing product. This result is very promising for the preparation of various glycosylated bambusurils and is thus opening the way to new multivalent platforms. ${ }^{[26]}$ Hence, for further applications, it could be interesting to have access to bambus[6]urils functionalized by biologically active molecules. 
Having in hand anion-containing bambus[6]urils functionalized by allyl 2-4, or thioether groups 9-16, we were interested in evaluating their association constants with various halide anions. To that end, the corresponding anionfree $\mathrm{BU}[6]$ had to be obtained. In the literature, several methods have already been reported to remove anion of the cavity of BU[6]. Typical examples include the exchange of the entrapped bromide by a less-strongly bound chloride anion using a huge excess of salt, ${ }^{[5]}$ followed by refluxing the CI@BU[6] complex in methanol. ${ }^{[3,5,9]}$ Alternatively, oxidation of the encaged iodide of $\mathrm{QBU}[6]$ to iodine, which is unable to interact with the macrocycle has also been proposed. ${ }^{[13]}$ It was reported that carboxyalkyl bambusurils complexes of $\mathrm{HSO}_{4}$ can be converted to their corresponding anion-free $\mathrm{BU}[6]$ by a treatment with basic water. ${ }^{[6]}$ More recently (trioxadecyl) ${ }_{12} \mathrm{BU}[6]$, bearing polyethylene glycol substituents and $\mathrm{TBABF}_{4}$, was obtained as its $\mathrm{NaBF}_{4}$ complex after purification by silicagel chromatography, ${ }^{[27]}$ and was obtained free of $\mathrm{BF}_{4}^{-}$anion by water continous extraction over 1 week. ${ }^{[8]}$ All these reported methods are burdensome and time consuming. It is worthy of note that chloride-free biotin[6]uril was obtained by treatment of its chloride complex with $\mathrm{TINO}_{3} \cdot{ }^{-[28]}$ although this procedure has never been applied to bambusurils. After unsuccessful attempts using these reported decomplexation processes, ${ }^{[3,9,13]}$ we set up a new method to obtain anion free allyl ${ }_{12} \mathrm{BU}[6] 17$

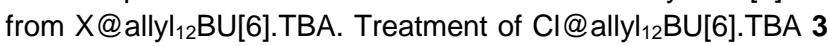
with silver hexafluoroantimonate $\mathrm{AgSbF}_{6}$ in $\mathrm{MeOH}$ generated instantaneously a white precipitate. This precipitate, containing allyl ${ }_{12} \mathrm{BU}[6] 17$ and $\mathrm{AgCl}$, was recovered by centrifugation. Washings with $\mathrm{NH}_{4} \mathrm{OH}$ solution allowed dissolution of $\mathrm{AgCl}$, while the insoluble anion-free ally ${ }_{12} \mathrm{BU}[6] 17$ was isolated by filtration (Scheme 6, 67\% yield). ${ }^{[29]}$

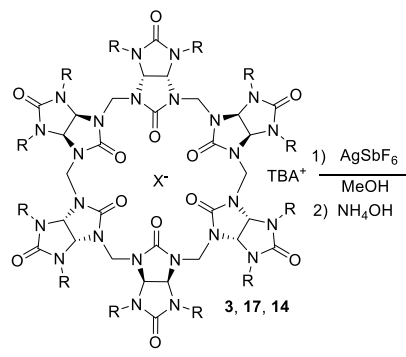

Cl@ally ${ }_{12} \mathrm{BU}_{6} \cdot \mathrm{TBA} 3, \mathrm{R}=\mathrm{CH}_{2}-\mathrm{CH}=\mathrm{CH}_{2}$ @ally| $\left.\right|_{12} \mathrm{BU}[6] . \mathrm{TBA} 2, \mathrm{R}=\mathrm{CH}_{2}-\mathrm{CH}=\mathrm{CH}_{2}$

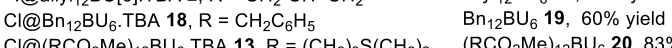
$\left(\mathrm{RCO}_{2} \mathrm{Me}\right)_{12} \mathrm{BU}_{6} \mathbf{2 0}, 83 \%$ yield $\mathrm{Br}(\mathrm{ROAC})_{12} \mathrm{BU}$. TBA 11, $\mathrm{R}=\left(\mathrm{CH}_{2}\right)_{3} \mathrm{~S}\left(\mathrm{CH}_{2}\right)_{2} \quad(\mathrm{ROAC})_{12} \mathrm{BU}_{6}$. TBA 21, $80 \%$ yield Scheme 6. New decomplexation method to prepare anion-free BU[6]17,1921

The release of the chloride anion from the bambusuril cavity was evidenced notably by the fact that allyl ${ }_{12} \mathrm{BU}[6] 17$ was not soluble in $\mathrm{CHCl}_{3}$, while Cl@allyl ${ }_{12} \mathrm{BU}[6]$.TBA 3 easily dissolves in $\mathrm{CHCl}_{3}$. Furthermore, ${ }^{19} \mathrm{~F}$ NMR and HRMS analyses of the isolated product confirmed the absence of residual $\mathrm{SbF}_{6}$ and the emptiness of the cavity. We therefore deduced that $\mathrm{SbF}_{6}{ }^{-}$interacts weakly with allyl ${ }_{12} \mathrm{BU}[6]$ 17. This was confirmed by ${ }^{1} \mathrm{H}$ NMR titration of 17 with either $\mathrm{AgSbF}_{6}$ or BMIm-SbF $_{6} \quad$ (BMIm $^{+}=1$-butyl-3-methylimidazolium) in $[D]_{6} D M S O$. The absence of ${ }^{1} \mathrm{H}$ NMR shift variations upon addition of large excess of both salts, is a proof of the very low affinity, if any, of $\mathbf{1 7}$ for the $\mathrm{SbF}_{6}-$ anion in DMSO. This is in accordance with the low binding constant of $\mathrm{SbF}_{6}-$ reported for $\mathrm{Bn}_{12} \mathrm{BU}[6]$ 19. in chloroform. [11c] DFT calculations strengthen our experiments as they show that the interaction of $\mathrm{SbF}_{6}$ - with allyl ${ }_{12} \mathrm{BU}[6] \mathbf{1 7}$ is also weak (see below for details and discussion). Finally, it is worthy to note that, while we used $\mathrm{NH}_{4} \mathrm{OH}$ in our procedure, the very hydrophilic hydroxide anion has in general negligible affinity for bambus[6]uril. ${ }^{[6]}$

Moreover, |@ally $\left.\right|_{12} \mathrm{BU}[6] @ T B A$ 2, enclosing an iodine anion in its cavity, was efficiently decomplexed to allyl ${ }_{12} \mathrm{BU}[6]$ 17 in $70 \%$ yield (Scheme 6). To prove the efficiency of $\mathrm{AgSbF}_{6}$ as an halide releasing reagent, the method was also applied to $\mathrm{Cl} @ \mathrm{Bn}_{12} \mathrm{BU}[6] . T B A$ 18. ${ }^{[30]}$ The known anion-free $\mathrm{Bn}_{12} \mathrm{BU}[6] 19$ was successfully isolated $(60 \%$ yield, Scheme 6$)$ and it exhibited spectroscopic features identical to those previously reported by Sindelar. ${ }^{[3]}$ Similarly, treatment of $\left.\mathrm{Cl} @\left(\left(\mathrm{CH}_{2}\right)_{3} \mathrm{~S}\left(\mathrm{CH}_{2}\right)_{2} \mathrm{CO}_{2} \mathrm{Me}\right)\right)_{12} \mathrm{BU}[6]$.TBA 13 with $\mathrm{AgSbF}_{6}$ provided anion-free BU[6] 20 (83\% yield, Scheme 6). Finally submission of $\left.\mathrm{Br} @\left(\left(\mathrm{CH}_{2}\right)_{3} \mathrm{~S}\left(\mathrm{CH}_{2}\right)_{2} \mathrm{OAc}\right)\right)_{12} \mathrm{BU}[6] . T \mathrm{BA} 11$ to decomplexation, afforded anion-free BU[6] 21 (80\% yield, Scheme 6). These results show that this facile and efficient decomplexation method can be employed to easily remove halide $(\mathrm{I}, \mathrm{Br}$ or $\mathrm{Cl})$ in various organic solvent soluble bambus[6]urils.

Binding properties of allyl ${ }_{12} \mathrm{BU}[6]$ 17, $\left.\left(\left(\mathrm{CH}_{2}\right)_{3} \mathrm{~S}\left(\mathrm{CH}_{2}\right)_{2} \mathrm{CO}_{2} \mathrm{Me}\right)\right)_{12} \mathrm{BU}[6] \quad 20$ and $\left.\left(\left(\mathrm{CH}_{2}\right)_{3} \mathrm{~S}\left(\mathrm{CH}_{2}\right)_{2} \mathrm{OAc}\right)\right)_{12} \mathrm{BU}[6] 21$ with chloride and iodide anions were then explored. Experimental and processing details are provided in the Supporting Information.

In the absence of anion, the $\mathrm{N}-\mathrm{CH}$ protons of the glycoluril units of allyl ${ }_{12} \mathrm{BU}[6] 17$ resonate at $5.44 \mathrm{ppm}$ in [D] ${ }_{6} \mathrm{DMSO}$ (signal b) on Figure 3a, 0 eq., full spectrum supplied in Figure S1). In the presence of TBAI, giving |@allyl ${ }_{12} \mathrm{BU}[6]$.TBA 2, these $\mathrm{N}-\mathrm{CH}$ protons resonate at $5.56 \mathrm{ppm}$ (signal a on Figure 3a, 0.4-3.2 eq.). The binding constant of $1-@ 17$ is rather low, close to $5 \times 10^{3} \mathrm{M}^{-1}$ (Figure S1), compared to that reported for $\mathrm{I}^{-}$ $@ \mathrm{Bn}_{12} \mathrm{BU}[6] 19$ in $\mathrm{CDCl}_{3}$, which is in the range $4 \times 10^{9}-3 \times 10^{10}$ $\mathrm{M}^{-1}{ }^{[3,11 \mathrm{c}]}$ We hypothesize that this far lower binding constant may be due to a significant competition with DMSO. This is based on above reported quantum chemistry calculations showing that DMSO is more stabilized in 17 cavity than $\mathrm{CHCl}_{3}$ (Figure 4). Thus, despite its much lower stabilization than iodide into the cavity of 17 , DMSO, of $14 \mathrm{M}$ concentration as the solvent, may efficiently compete with the anion, of millimolar concentration, for complexation of the bambusuril. This is confirmed by the absence of modification of the chemical shift of the $\mathrm{N}-\mathrm{CH}$ protons of $\mathbf{1 7}$ during its titration with TBACI in DMSO, even with the addition of 24 equivalents of TBACl (Figure S2); this indeed denotes a very weak, if any, binding constant between 17 and chloride in DMSO. This is coherent with the results of Sindelar's group showing that in $\mathrm{CDCl}_{3}$, the chloride inclusion complex with $\mathrm{Bn}_{12} \mathrm{BU}[6] 19$ is about $10^{3}$ times less stable than the corresponding iodide one. ${ }^{[3]}$ This is also in agreement with the titration of Cl@allyl ${ }_{12} \mathrm{BU}[6] 3$ with TBAI in $\mathrm{CDCl}_{3}$, showing that iodide 
binds at least 120 times more strongly to allyl ${ }_{12} \mathrm{BU}[6] 17$ than chloride does (Figure S3).
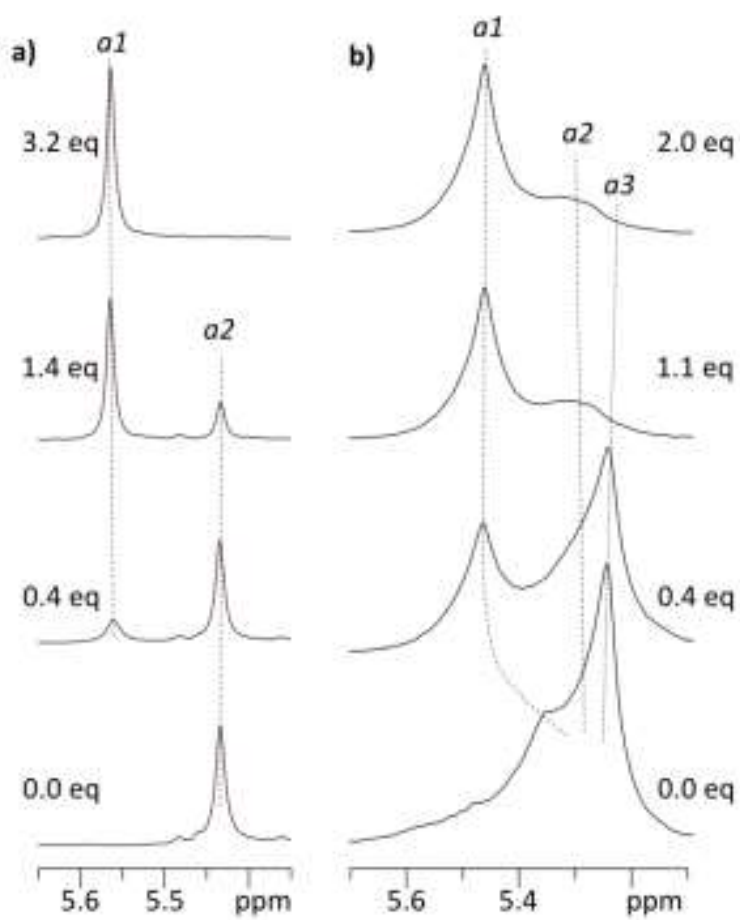

Figure 3. Titration of ally $\left.\right|_{12} \mathrm{BU}[6] 17$ giving complex |@ally $\mathrm{l}_{12} \mathrm{BU}[6] . T \mathrm{BA} 2$ (Fig 6a) and of $\left.\left(\left(\mathrm{CH}_{2}\right)_{3} \mathrm{~S}\left(\mathrm{CH}_{2}\right)_{2} \mathrm{CO}_{2} \mathrm{Me}\right)\right)_{12} \mathrm{BU}[6] 20$ giving complex @@ $\left(\left(\mathrm{CH}_{2}\right)_{3}-\mathrm{S}-\left(\mathrm{CH}_{2}\right)_{2} \mathrm{CO}_{2} \mathrm{Me}\right)_{12} \mathrm{BU}[6]$.TBA 12 (Fig 6b) in [D]6 $]_{6} \mathrm{DMSO}$ with TBAl. Parts of ${ }^{1} \mathrm{H}$ NMR spectra corresponding to $\mathrm{NCH}$ protons. Dashed lines are guidelines for signals a1, a2 and a3, see text. Full spectra are provided in SI (see Figures S2 and S6).

The situation is more complicated when $\left(\left(\mathrm{CH}_{2}\right)_{3} \mathrm{~S}\left(\mathrm{CH}_{2}\right)_{2}\right.$ $\left.\mathrm{CO}_{2} \mathrm{Me}\right){ }_{12} \mathrm{BU}[6] 2 \mathrm{O}$ is concerned. In the ${ }^{1} \mathrm{H}$ NMR spectrum of $\mathrm{Cl} @\left(\left(\mathrm{CH}_{2}\right)_{3} \mathrm{~S}\left(\mathrm{CH}_{2}\right)_{2} \mathrm{CO}_{2} \mathrm{Me}\right)_{12} \mathrm{BU}[6]$.TBA 13 in $\mathrm{CDCl}_{3}$, the signals assigned to $\mathrm{N}-\mathrm{CH}-\mathrm{N}$ protons of the glycoluril units and to $\mathrm{N}-\mathrm{CH}_{2}-\mathrm{N}$ protons between two glycoluril units have a complex shape spanning a range of 0.25 to $0.3 \mathrm{ppm}$ (Figure S4). In the course of the titration of $\mathbf{2 0}$ with TBAI, these shapes are modified and signals tend to be sharper, particularly at the end of the titration, when the complex I@BU[6] 12 prevails in solution. Furthermore, iodide is at least a 40 times better guest than chloride to $\mathbf{2 0}$ (Figure S4), a result consistent with the known higher affinity of bambus[6]urils for iodide versus chloride anions. ${ }^{[5,11 c, 13,31]}$ These observations are consistent with the following hypothesis: the long and flexible arms of $\left(\left(\mathrm{CH}_{2}\right)_{3} \mathrm{~S}\left(\mathrm{CH}_{2}\right)_{2} \mathrm{CO}_{2} \mathrm{Me}\right)_{12} \mathrm{BU}[6] 20$ are able to explore the BU's cavity, competing with anions used for titration, whereas shorter arms in allyl ${ }_{12} \mathrm{BU}[6] 17$ cannot explore the cavity. This exploration induces conformational variation at the millisecond timescale of the cavity of 20 , resulting in large ${ }^{1} \mathrm{H}$ NMR signals. Competition between flexible arms and anion inside the cavity turns out to be more in favor of the iodide complex 12, than when chloride complex $\mathbf{1 3}$ is concerned, explaining the sharper signals for complex 12. Moreover, iodide, a bigger anion than chloride, should stabilize the cavity in a more rigid conformation. Finally, the NMR spectra obtained during the titration of $\mathrm{Cl} @ a$ allyl ${ }_{12} \mathrm{BU}[6] 3$ with TBAI giving I@allyl ${ }_{12} \mathrm{BU}[6] 2$ (Figure S3) exhibit sharp and well-defined signals, tending to show that shorter arms are unable to explore the bambusuril cavity. It is in agreement with titrations of $\mathrm{Bn}_{12} \mathrm{BU}[6] \mathrm{19}$, another bambusuril with short arms, ${ }^{[3,11 c]}$ and with previous observations dealing with the influence of the length of carboxylic arms in other $\mathrm{BU}[6]$ derivatives. ${ }^{[6]}$

The titration of $\left.\left(\left(\mathrm{CH}_{2}\right)_{3} \mathrm{~S}\left(\mathrm{CH}_{2}\right)_{2} \mathrm{CO}_{2} \mathrm{Me}\right)\right)_{12} \mathrm{BU}[6] 20$ with TBAI in DMSO is the most complex situation, as three competitors are involved for the access to the cavity of $\mathbf{2 0}$, namely, the iodide anion, the long and flexible arms and the solvent. The spectral complexity observed in the course of the titration is in agreement with this interpretation (Figure 3b, spectra of the full titration in Figure S5). As an example of this complexity, three signals characteristic of $\mathrm{N}-\mathrm{CH}$ protons are observed and experience chemical shifts and line-width variations during the titration (signals a1, a2 and a3 in Figure 3b). a1 signal increases in intensity during the titration of $\mathbf{2 0}$ with TBAI and is therefore assigned to $\mathrm{N}-\mathrm{CH}$ protons in formed complex $\left.\mathrm{Q}\left(\left(\mathrm{CH}_{2}\right)_{3} \mathrm{~S}\left(\mathrm{CH}_{2}\right)_{2} \mathrm{CO}_{2} \mathrm{Me}\right)\right)_{12} \mathrm{BU}[6]$ 12. The chemical shift variation of a1 signal reflects a relatively fast exchange process corresponding to the binding competition between the three competitors. a2 signal is persistent throughout the titration, even after the addition of 60 equivalents of TBAI. A broadening of signal a2 is observed by increasing the temperature (Figure S6a). This suggests that signal a2 corresponds to a minor conformer with a lifetime decreasing with temperature. Moreover, the line-width of a2 signal increases with the concentration of bambusuril (Figure S6b). This concentration-dependence suggests that signal a2 corresponds to $\mathrm{N}-\mathrm{CH}$ protons of self-aggregated bambusurils. Indeed, a2 signal is relative to intermolecular interactions between the long and flexible arms of cage $\mathbf{1 2}$ and the cavity of the neighboring molecule that might stabilize such assemblies. ${ }^{[35]}$ Finally, a3 signal becomes undetectable with a strong excess of TBAI (Figure 3b). a3 signal is thus assigned to $\mathrm{N}-\mathrm{CH}$ protons of $\mathrm{BU}[6] 20$. The complexity of this system prevents the binding constant to be estimated from either the chemical shift variations or the intensity changes of any ${ }^{1} \mathrm{H}$ NMR signal. This complexity is however fully consistent with the competition of anions, solvent molecules and long and flexible arms for their occurrence in $\mathrm{BU}[6]$ cavities.

The titration of $\left.\left(\left(\mathrm{CH}_{2}\right)_{3} \mathrm{~S}\left(\mathrm{CH}_{2}\right)_{2} \mathrm{OAc}\right)\right)_{12} \mathrm{BU}[6] 21$ with TBACl in acetone denotes also complex phenomena (Figure S7). The $\mathrm{N}-\mathrm{CH}_{2}$ signal indicates a slow exchange between two environments even in the absence of chloride. When TBACl is added to 21 , the down-field shifted signal is increasing rapidly and becomes predominant with 0.5 equivalent of TBACl. This signal is assigned to the $\mathrm{N}-\mathrm{CH}_{2}$ protons bordering the cavity of 21 binding either chloride, or a long and flexible $\left(\mathrm{CH}_{2}\right)_{3} \mathrm{~S}\left(\mathrm{CH}_{2}\right)_{2} \mathrm{OAc}$ arm of 21. The up-field shifted signal is assigned to those same protons of an empty BU[6] 21 or of $\mathbf{2 1}$ binding a solvent molecule. This signal is significantly broaden even at only 0.5 equivalent of $\mathrm{TBACl}$ showing the short lifetime of the corresponding environment. A competition between arms and chloride supports this observation, although a 
quantification of binding constants cannot be obtained. However, when bambusuril 21 containing 1.15 equivalent of TBACl is titrated by TBAI, a slow exchange is observed on $\mathrm{N}$ $\mathrm{CH}$ signal (Figure S8). This denotes a competition between guests. Both signals are assigned to (i) bambusuril 21 binding chloride or a thioether arm, and (ii) iodide, respectively. Using $\mathrm{N}-\mathrm{CH}_{2}$ signal, also in slow exchange but much closer to the coalescence, it has been deduced that iodide is a better guest than chloride to bambusuril $\mathbf{2 1}$ but only by a factor 4 (the fit is in accordance with values in the range 3-15). We note that this is a lesser ratio than that observed in the case of ally ${ }_{12} \mathrm{BU}[6]$ 17, bearing much smallest arm. This might be due to the competition of the anion with arms to the bambusuril binding, non-negligible even when the anion is iodide, one of the most stable guest of bambusurils ever observed. This will be explore in more details in the future.

DFT calculations were set up for a better understanding of the stability of the halides@allyl ${ }_{12}[\mathrm{BU}]$ complexes 2-4 and the relevance of our decomplexation method using $\mathrm{AgSbF}_{6}$ (see Supporting Information for details).

The factors determining the stability of the ally| ${ }_{12} \mathrm{BU}[6] 17$ complexes can be best visualized by applying an energy decomposition analysis scheme (see Figure 4 and Supporting Information for details and Table 1).

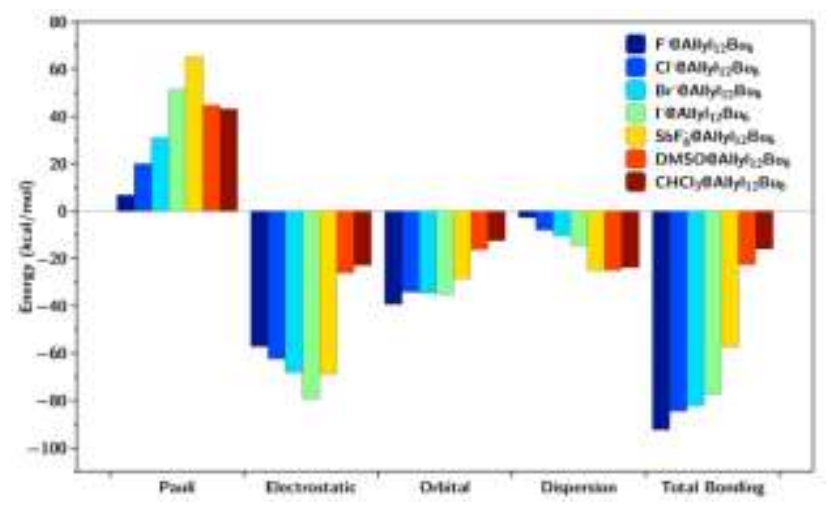

Figure 4. ZORA-DFT/PBE0-D3(BJ) bonding energy analysis with respect to the anion and bambus[6]uril fragments.

The dominating contribution to the interaction energy stems from the electrostatic interaction (ca $60 \%$ to the total attractive interactions), followed by the orbital interaction (ca $20-40 \%$ to the total attractive interactions). Positive values of the molecular electrostatic potential (MEP) were obtained inside the cavity of allyl $_{12} \mathrm{BU}[6] 17$ (Figure 5), demonstrating the ability of the receptor to bind negatively charged groups or anions and explaining the dominance of the electrostatic term in the intermolecular stabilization.

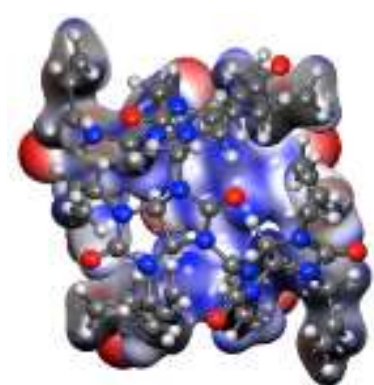

Figure 5. Calculated (DFT/B97-D3(BJ), def2-TZVP) molecular electrostatic potential of allyl ${ }_{12} \mathrm{BU}[6] 17$ mapped onto an isodensity surface of $0.02 \mathrm{e}^{-3}$. Positive values in blue, negative values in red.

To a lesser extent, the presence of the $\mathrm{CH} . . \mathrm{X}$ and dispersion interactions also contribute to the stability of the complexes. This can be easily deduced from a non-covalent interaction analysis ( $\mathrm{NCl}$ ) (Figure 6, see Supporting Information for details). Pauli repulsion energy (Figure 4) increases in the halogen series from $\mathrm{F}^{-}$to $\mathrm{I}^{-}$following the same trend as the ionic radii.

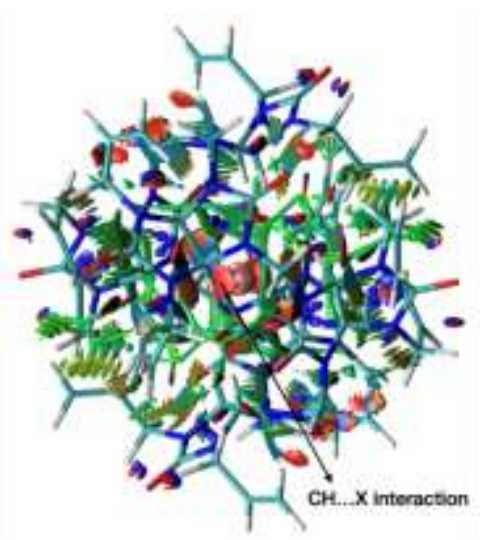

Figure 6. Spatial regions of non-covalent interaction of $1-@ a l l y l_{12} \mathrm{BU}[6] 2$. The attraction regions are shown in red, the van der Waals in green and the repulsion in blue. The $\mathrm{CH}$...X bonds are clearly identified between $\mathrm{H}$ and $\mathrm{I}$.

Then we used DFT calculations to support our above reported experimental findings, using $\mathrm{AgSbF}_{6}$ as reagent to remove anion from the cavity of $\mathrm{BU}[6]$. DFT calculations confirm that the interaction of $\mathrm{SbF}_{6}$ - with allyl ${ }_{12} \mathrm{BU}[6] 17$ is also weak. These experimental findings are in contrast with the actual cavity size computed for anion-free allyl ${ }_{12} \mathrm{BU}[6] 17$ (ca. $139 \AA^{3}$ ) which should be large enough to encapsulate $\mathrm{SbF}_{6}$ anion (ca. $82 \AA^{3}$, see Figure S9 for details). The volume of the latter is in agreement with the recently reported values of 81.8 $\AA^{3}{ }^{[31]}$ and $75 \AA^{3}{ }^{[32]}$ and moreover lies close to the volume of the iodide anion $\left(72 \pm 16 \AA^{3}\right) .^{[3]}$ If one compares the complexation ability of $\mathbf{1 7}$ towards $\mathrm{SbF}_{6}{ }^{-}$and $\mathrm{I}^{-}$, it becomes obvious that the size effect is not enough to account for the difference in binding affinity. Quantum chemistry calculations performed on $\mathrm{SbF}_{6}-$ uptake by 17 indicate the formation of a stable $\mathrm{SbF}_{6} @$ allyl $_{12} \mathrm{BU}[6]$ complex. This complex has a significantly lower stabilization energy $(-57 \mathrm{kcal} / \mathrm{mol})$ than that with iodide (I@ally $\left.{ }_{12} \mathrm{BU}[6] 2,-77 \mathrm{kcal} / \mathrm{mol}\right)$, which is mainly 
due to a higher Pauli repulsion term and a lower stabilizing electrostatic term in $\mathrm{SbF}_{6}$ @@allyl ${ }_{12} \mathrm{BU}[6]$ (see Figure 4).

Quantum chemistry calculations evidence also a weak energy stabilization of DMSO with allyl ${ }_{12} \mathrm{BU}[6] \quad 17 \quad(-22$ $\mathrm{kcal} / \mathrm{mol}$ ), due to a partial polarization of its $\mathrm{S}=\mathrm{O}$ bond, inducing a negative charge on the oxygen atom. However, when used as a solvent, DMSO may compete efficiently with anions binding into the $\mathrm{BU}[6]$ cavity. $\mathrm{CHCl}_{3}$ is slightly less stabilized than DMSO upon complexation with a binding energy of $-16 \mathrm{kcal} / \mathrm{mol}$ with 17 and a similar interaction energy pattern (see Figure 4).

\section{Conclusion}

In summary, thioether-functionalized $\mathrm{BU}[4]$ and $\mathrm{BU}[6]$ were synthesized by thiol-ene coupling reactions of ally $\mathrm{l}_{8} \mathrm{BU}[4]$ and allyl ${ }_{12} \mathrm{BU}[6]$. These new functionalized (RS) $)_{8} \mathrm{BU}[4]$ and (RS) ${ }_{12} \mathrm{BU}[6]$, with an alternate spatial arrangement of glycoluril building blocks, might find applications as scaffolds to build multivalent systems with 8 to 12 ligands or inhibitors. We report that the nature of the anion enclosed in the cavity of allyl ${ }_{12} \mathrm{BU}[6]$ modifies the reactivity of the allyl arms linked to the portal. Indeed, I@allyl ${ }_{12} B U[6] . T B A$ was shown to be less reactive towards thiol-ene and hydrogenation reactions than Cl@allyl ${ }_{12} \mathrm{BU}[6] . T B A$ and Br@allyl ${ }_{12} \mathrm{BU}[6] . T B A$ that enclosed a chloride or a bromide anion respectively. A new, facile method making use of silver hexafluoroantimonate has been set up to remove halide enclosed in the cavity of BU[6]. Anion-free bambus[n]urils were isolated in good yields (60-83\%) and their complexation properties with different anions were studied by ${ }^{1} \mathrm{H}$ NMR spectroscopy, revealing a strong influence of the solvent. Binding constants are much lower in DMSO than in chloroform. This may come from the higher capacity of DMSO than $\mathrm{CHCl}_{3}$ to be incorporated in the cavity of $\mathrm{BU}[6]$, resulting in stronger competition with anions. Thioether groups grafted on bambusuril portals act as competitors to anions for binding to the cavity of $\mathrm{BU}[6]$. A work on the binding and competition studies of bambus[6]urils functionalized by long and flexible arms is on going in our laboratory. Indeed, these twelve long and flexible arms induce self-assembly of the BU[6] in solution, a phenomenon that will be studied in more details in the near future. Quantum chemistry calculations were useful to bring additional information to experiments and to gain an understanding of the host-guest interactions. Solely referring to the volume of the anion does not make possible to understand the affinities observed experimentally and a thorough analysis of the interactions involved is required. The design of new $\mathrm{BU}[6]$ is in progress, to improve their affinity with anions with the aim to use them as sensors for further chemical or biological applications.

\section{Acknowledgements}

We thank the doctoral school ED 571, 2MIB, program COB, University of Paris Saclay for providing a MENESR fellowship to D. A. The program "NEEDS Blanc" (project BAMBIDETEX) was thank for financially support. We are grateful to Dr. T. Le Gall (CEA/DRF/JOLIOT/SCBM) for reviewing the manuscript, to $\mathrm{Dr} Y$. Boulard (CEA/I2BC/SCBM/LBSM) for recording 600
MHz NMR spectra and to Dr F. Fenaille (CEA/DRF/JOLIOT/SPI/LEMM) for Mass spectroscopy experiments.

\section{Keywords: Bambusuril • Thiol-ene • Decomplexation • Quantum chemistry • NMR}

\section{References}

1 T. Lizal, V. Sindelar Isr. J. Chem. 2017 DOI: 10.1002/ijch.201700111

2 J. Svec, M. Necas, V. Sindelar Angew. Chem. Int. Ed. 2010, 49, 2378-2381.

3 V. Havel, J. Svec, M. Wimmerova, M. Dusek, M. Pojarova, V. Sindelar Org. Lett. 2011, 13, 4000-4003.

4 J. Rivollier, P. Thuéry, M.-P. Heck Org. Lett. 2013, 15, 480-483.

5 M. A. Yawer, V. Havel, V. Sindelar Angew. Chem. Int. Ed. 2015, 54 276-279

6 V. Havel, M. Babiak, V. Sindelar Chem. Eur. J. 2017, 23, 8963-8968.

7 M. A. Yawer, K. Sleziakova, L. Pavlovec, V. Sindelar Eur. J. Org. Chem. 2018, 1, 41-47.

8 T. Fiola, K. Sleziakova, K. Marsalek, K. Salvadori, V. Sindelar J. Org Chem. 2018, 83, 1903-1912.

$9 \quad$ M. Singh, E. Solel, E. Keinan, O. Reany Chem. Eur. J. 2015, 21, 536540 .

10 a) M. Singh, E. Solel, E. Keinan, O. Reany Chem. Eur. J. 2016, 22, 8848-8854. b) C. Lang, A. Mohite, X. Deng, F. Yang, Z. Dong, J. Xu J. Liu, E. Keinan, O. Reany Chem. Commun. 2017, 53, 7557-7560.

11 a) P. A. Denis, J. S. Gancheff Comput. Theor. Chem. 2013, 1023, 5 9. b) V. Havel, M. Arfan, V. Sindelar Chem. Commun. 2015, 51 4666-4669. c) V. Havel, V. Sindelar Chem. Plus Chem. 2015, 80, 1601-1606.

12 E. Solel, M. Singh, O. Reany, E. Keinan Phys. Chem. Chem. Phys. 2016, 18, 13180-13185.

13 J. Svec, M. Dusek, K. Fejfarova, P. Stacko, P. Klán, A. E. Kaifer, W Li, E. Hudeckova, V. Sindelar Chem. Eur. J. 2011, 17, 5605-5612.

14 a) J. J. McKinnon, A. S. Mitchell, M. A. Spackman, Chem.-Eur. J. 1998, 4, 2136-2141; b) M. A. Spackman, J. J. McKinnon, CrystEngComm 2002, 4, 378-392; c) J. J. McKinnon, M. A. Spackman, A S. Mitchell, Acta Crystallogr., Sect. B 2004, 60, 627668 ; d) J. J. McKinnon, D. Jayatilaka, M. A. Spackman, Chem. Commun. 2007, 3814-3816; e) M. A. Spackman, D. Jayatilaka, CrystEngComm 2009, 11, 19-32; f) M. A. Spackman, Phys. Scr. 2013, 87, 048103 (12 pp).

15 S. K. Wolff, D. J. Grimwood, J. J. McKinnon, M. J. Turner, D. Jayatilaka, M. A. Spackman, CrystalExplorer, University of Western Australia, 2012.

16 R. Taylor, Cryst. Growth Des. 2016, 16, 4165-4168, and references therein.

17 a) T. Steiner, Acta Cryst., Sect. B 1998, 54, 456-463; b) L. Brammer, E. A. Bruton, P. Sherwood, Cryst. Growth Des. 2001, 1, 277-290.

18 a) C. E. Hoyle, C. N. Bowman Angew. Chem. Int. Ed. 2010, 49, 1540 1573; b) A. Dondoni Angew. Chem. Int. Ed. 2008, 47, 8995-8997; c) R. Hoogenboom Angew. Chem. Int. Ed. 2008, 120, 9133-9135; d) N. Bowman, Chem. Soc. Rev. 2010, 39, 1355-1387; e) K. L. Killops, L. M. Campos, C. J Hawker J. Am. Chem. Soc. 2008, 130, 5062-5064.

19 M. Akikazu, K. Takeshi J. Patent JP 2016164134, 08 Sep 2016.

20 J. Kim, Y. Ahn, K. Min Park, Y. Kim, Y. Ho Ko, D. Hyun Oh, K. Kim. Angew. Chem. Int. Ed. 2007, 46, 7393-7395.

21 M. Uygun, M. A. Tasdelen, Y. Yagci Macromol. Chem. Phys. 2010, $211,103-110$.

22 Products $7 \mathrm{a}, 7 \mathrm{7e}$ and $7 \mathrm{f}$ were prepared by TEC activated by UV. Other thiols were not submitted to UV initiation.

23 G. Povie, A.-T. Tran, D. Bonnaffé, J. Habegger, Z. Hu, C. Le Narvor, P. Renaud Angew. Chem. Int. Ed. 2014, 53, 3894-3898.

24 L. Lazar, M. Nagy, A. Borbas, P. Herczegh, M. Zsuga, S. Kéki Eur. J. Org. Chem. 2015, 7675-7681.

Org. Chem. 2015, 7675-7681.
This complex mixture was not further analyzed.

26 Some glycosylated bambusurils were recently prepared in our laboratory and their synthesis and biological results will be reported elsewhere soon.

27 Although our BU[6].TBAX $(\mathrm{X}=\mathrm{I}, \mathrm{Cl}, \mathrm{Br})$ compounds were purified by silicagel column chromatography using $\mathrm{CH}_{2} \mathrm{Cl}_{2} / \mathrm{MeOH}$ as mobile phase, this cation exchange was not observed by us.

28 M. Lilsbjerg, B. M. Jessen, B. Rasmussen, B. E. Nielsen, A. Madsen, M. Pittelkow Chem. Sci. 2014, 5, 2647-2650. 
29 First a procedure using $\mathrm{AgNO}_{3}$ instead of $\mathrm{AgSbF}_{6}$ was tested on Cl@allyl $\mathrm{l}_{12} \mathrm{BU}[6] . T B A$ 4. The resulting BU[6] was soluble in DMSO affording a well-resolved ${ }^{1} \mathrm{H}$ NMR spectrum. We suppose that $\mathrm{NO}_{3}$ @allyl ${ }_{12} \mathrm{BU}[6] . T B A$ was formed instead of the desired anion-free $\mathrm{BU}[6]$. Addition of $\mathrm{TBANO}_{3}$ to anion-free allyl ${ }_{12} \mathrm{BU}[6] 16$ afforded the same product identified as $\mathrm{NO}_{3} @$ allyl ${ }_{12} \mathrm{BU}$ [6].TBA. Furthermore, $\mathrm{K}_{\mathrm{a}}$ of $\mathrm{NO}_{3}^{-}$with $\mathrm{Bn}_{12} \mathrm{BU}[6]$ in $\mathrm{CHCl}_{3}$ was reported to be $2 \times 10^{9} \mathrm{M}^{-1}$, see ref [14c]

$30 \quad \mathrm{Bn}_{12} \mathrm{BU}[6] 18$ was prepared following our microwaves procedure described in ref [4]. Spectroscopic data are in close agreement with the values reported by Sindelar in ref [3]

31 S. Kaabel, J. Adamson, F. Topić, A. Kiesilä, E. Kalenius, M. Öeren, M. Reimund, E.Prigorchenko, A. Lõokene, H. J. Reich, K. Rissanen, R. Aav Chem. Sci. 2017, 8, 2184-2190.
32 D. G. Georgiadou, L. C. Palilis, M. Vasilopoulou, G. Pistolis, D. Dimotikali, P. Argitis Synthetic Metals, 2013, 181, 37-44.

33 a) H. D. B. Jenkins, H. K. Roobottom, J. Passmore, L. Glasser Inorg. Chem. 1999, 38, 3609-3620. b) The volume of $\mathrm{SbF}_{6}{ }^{-}\left(121 \pm 112 \AA^{3}\right)$ estimated by Jenkins et al in [33a] is quite different from us and refs [31], [32] but it is affected by a huge deviation in ref [33a].

34 A. Révész, D. Shröder, J. Svec, M. Wimmerova, V. Sindelar J. Phys. Chem. A. 2011, 115, 11378-11386.

35 V. Lewin, J. Rivollier, S. Coudert, D.-A. Buisson, D. Baumann, B. Rousseau, F.-X. Legrand, H. Kouřilová, P. Berthault, J.-P. Dognon, M.-P. Heck, G. Huber. Eur. J. Org. Chem. 2013, 3857-3865. 